\title{
Encontros no campo do turismo solidário do Vale do Jequitinhonha (Minas Gerais, Brasil)
}

\author{
Meetings in the field of solidarity tourism of Vale do Jequitinhonha \\ (Minas Gerais, Brazil)
}

\author{
Rafael Ângelo Fortunato (FORTUNATO, R. A.)
}

\begin{abstract}
RESUMO - O artigo investiga o turismo solidário no Vale do Jequitinhonha (Minas Gerais, Brasil) com foco nas relações interpessoais e nos encontros entre turistas solidários e população local. O turismo solidário é um conceito em formação e apresenta-se aliando ações voluntárias eventuais e a proposta de valorização do saber local, da autogestão e da troca de experiências. Parte-se da premissa que o encontro e os graus de intimidade estabelecidos nos encontros ampliam as experiências desses sujeitos e o campo de possibilidades de ressignificação de suas identidades. O estudo adota a abordagem qualitativa operando-se com observação participante e entrevistas semiestruturadas. No processo investigatório foram estabelecidos cinco níveis de intimidade, em uma gradação crescente, que permite entender quais as temáticas discutidas nos encontros e como elas mudam e ganham novas dimensões de acordo com o aumento da intimidade. No nível mais elevado, a variedade de temas discutidos nos encontros são maiores e as negociações para trocas de temas são mais dinâmicas, o que faz emergir experiências inusitadas que contribuem para a resignificação identitária dos sujeitos da interação.
\end{abstract}

Palavras-chave: Turismo solidário; Encontro; Identidade.

ABSTRACT - The article investigates the solidarity tourism in the Vale do Jequitinhonha (Minas Gerais, Brazil) with a focus on interpersonal relationships and in meetings between solidary tourists and local population. The solidarity tourism is a concept in evolution and it is presented combining voluntary actions and the proposal of appreciation of local knowledge, the self-management and the experiences exchange. It starts with the premise that the meeting and the degrees of intimacy established in the meetings enlarge the experiences of these subjects and the range of possibilities of reframing their identities. The study adopts a qualitative approach operating with participant observation and semi-structured interviews. In the process of investigation were established five levels of intimacy in an increasing graduation, which allowed to understand what the issues discussed in the meetings and how they change and gain new dimensions according to the intimacy increasing. At the highest level, the variety of topics discussed in the meetings are larger and the negotiations for exchanging themes are more dynamic, which brings out unusual experiences that contribute to reframing the identity of the interaction subject.

Key words: Solidarity tourism; Meeting; Identity.

\footnotetext{
* Graduação em Turismo (Bacharelado) pela Universidade de Marília-SP (UNIMAR), Especialização em Educação Ambiental pela Faculdade de Saúde Pública da Universidade de São Paulo (USP), Mestrado em Desenvolvimento Regional e Meio Ambiente pelo Centro Universitário de Araraquara-SP, Doutorado em Meio Ambiente pelo Programa de Pós-graduação em Meio Ambiente da Universidade do Estado do Rio de Janeiro (UERJ). Professor Adjunto da Universidade Estadual do Rio de Janeiro (UERJ/IGEOG/DTUR). Endereço para contato: Rua Conselheiro Olegário, 37, 401, CEP: 20271-090. Rio de Janeiro - Rio de Janeiro (Brasil). Telefone para contato: 21-83474100. E-mail: rafael.fortunato@uerj.br
} 


\section{INTRODUÇÃO}

Considerado um fenômeno social, o turismo pode ser estudado por diferentes campos do conhecimento (educação, sociologia, filosofia, antropologia, literatura poética, dentre outros) constituindo-se como um objeto transdisciplinar. Considerando essas diferentes perspectivas, este artigo apresenta os encontros entre os "turistas solidários" e a população local que ocorrem no âmbito do Programa de Turismo Solidário do Vale do Jequitinhonha (Minas Gerais, Brasil). (TURISMOSOLIDÁRIO, 2012).

O Vale é uma das regiões mais pobres do país, sendo conhecida também, no senso comum, como o "Vale da miséria". Várias ações propostas no programa contribuem para o enfrentamento da pobreza no local como, por exemplo, o fortalecimento da vida comunitária e a promoção de atividades de artesanato e de turismo. Lançado pelo governo do estado de Minas Gerais, esse Programa opera na perspectiva de que o turista possa conhecer a região e trocar experiências com a população hospedando-se em um "receptivo familiar" - modo como é referida a residência de moradores locais disponibilizadas para recebimento de turistas (TURISMOSOLIDÁRIO, 2012). Segundo relatos dos agentes do Programa, o que caracteriza o "turista solidário" é o fato de ele ficar hospedado nas casas dos moradores e estar disposto para estabelecer relações de estima recíproca nos encontros e trocar experiências, independente da prática de ações voluntárias.

No sítio eletrônico citado acima aonde o Programa é apresentado encontram-se algumas referências que fundamentam tal assertiva, como por exemplo: "O programa consiste em despertar no turista solidário um sentimento humanista para ajudar diretamente no desenvolvimento da região" ou ainda: “O Programa Turismo Solidário é puro intercâmbio. Mágico contato dos diferentes num desejo frenético de aprender, trocar, vivenciar, respeitar o inusitado, vindo de todas as partes e de todos os lados". Estas descrições estabelecem relações diretas com a busca por parte do turista de viver uma experiência de aproximação com a população local. Victor Turner e Edith Turner (1978) chamam experiências deste tipo de busca pela communitas que, segundo Steil (2003), podem ser expressas pela tentativa de se alcançar uma comunhão fusional. 
Neste artigo, discute-se o fenômeno turístico com ênfase na interação e no contínuo aumento de intimidade presente nos encontros entre os "turistas solidários" e a população local, com objetivo de elencar as variedades de temas discutidos nos encontros e suas potencialidades.

Os significados dos encontros que ocorrem no âmbito do turismo solidário do vale do Jequitinhonha podem ser visualizados com maior profundidade em um estudo de Fortunato e Neffa (2010a). Os aspectos conceituais e políticos do Programa são apresentado em outro artigo de Fortunato e Neffa (2010b).

A delimitação teórica deste estudo parte da premissa de que o encontro e os graus de intimidade estabelecidos nos mesmos ampliam as experiências desses sujeitos e o campo de possibilidades de ressignificação de suas identidades.

A pesquisa de campo constituiu-se no processo de imersão do pesquisador em quatro localidades do vale do Jequitinhonha (Capivari, São Gonçalo do Rio das Pedras, Mendanha e Alecrim) durante três anos em temporadas semanais para levantamento de dados da pesquisa. Nesse período, foram visitados cerca de vinte "receptivos familiares" e entrevistados 25 turistas.

A permanência/hospedagem do investigador no cenário da pesquisa facilitou o recebimento do aval dos "administradores do receptivo", o que permitiu a circulação por outros receptivos, por associação de moradores e em escolas, dentre outros equipamentos sociais.

A adoção da abordagem fenomenológica ${ }^{1}$ para interpretação dos casos ocorridos no campo de pesquisa deu-se por essa corrente filosófica "apreender a essência do fenômeno", no caso desta pesquisa, dos encontros que ocorreram no campo do turismo solidário, e, em um segundo momento, por orientar o pesquisador para uma busca de significados que ele intui ou detecta.

Para Husserl (2008), a fenomenologia encarrega-se da tarefa de manter a consciência reflexiva diante dos objetos. Nessa esteira interpretativa, Machado (1994, p. 45) constata que "as percepções que os sujeitos têm da sua experiência vivida passam a

\footnotetext{
${ }^{1}$ O esforço filosófico de Husserl (1859-1938) orienta-se para a discussão da situação gerada pelo positivismo: a crise da filosofia, a crise das ciências e a crise das ciências humanas, que torna urgente o repensar sobre os fundamentos e a racionalidade dessas disciplinas, mostrando que tanto a filosofia quanto as ciências humanas são viáveis. A proposta retoma a questão da relação sujeito-objeto, colocada pelo racionalismo cartesiano que enfatiza o papel atuante do sujeito que conhece e o empirismo. $\mathrm{O}$ resultado dessa dicotomia, em ambos os casos, é a permanência do dualismo matéria-espírito e ser humano-mundo (HUSSERL, 2008).
} 
constituir os dados da pesquisa ou as 'unidades de significado' que compõem os elementos estruturais do fenômeno".

Ao afirmar que toda consciência é intencional, Husserl (2008) salienta que não há pura consciência separada do mundo, mas que toda consciência tende para o mundo. Da mesma forma, não há objeto em si, independente de uma consciência que o perceba, pois o objeto é um fenômeno, "algo que aparece" para uma consciência. Atinge-se a essência das coisas descrevendo-se a experiência tal como ela se processa.

Para que assim ocorra, Husserl (2008) recomenda a suspensão de todo o juízo de valor sobre os objetos e uma atitude de abandono do mundo e recolhimento do indivíduo dentro de si mesmo.

Para a fenomenologia não há fatos com a objetividade pretendida, pois não se percebe o mundo como um dado bruto, desprovido de significados, mas a partir da percepção do sujeito que o percebe. Daí a importância dada à rede de significações que envolvem os objetos percebidos: a consciência "vive" imediatamente como doadora de sentido.

A fenomenologia busca a essência do fenômeno por meio de uma dedução sistemática do fenômeno em unidades de significado. No entanto, a fenomenologia não pretende demonstrar, sua preocupação consiste em revelar. Para Capalbo (1987, p. 1), “as essências se referem ao sentido do ser do fenômeno". A análise intencional no campo da fenomenologia revela que o objeto é constituído como significante e compete à fenomenologia entender este processo constitutivo.

Desse modo, para interpretar os dados obtidos na pesquisa, estabeleceram-se algumas unidades de significado que revelaram as temáticas discutidas na interação, tendo como variável o aumento do grau de intimidade que permitiu maior fluidez nas negociações e um alargamento da percepção do indivíduo, visto que as "cegueiras" de um podem ser minimizadas pela capacidade de ver do outro, portador de outras “cegueiras" (OLIVEIRA, 2007).

No segundo tópico deste artigo apresentam-se concepções em torno dos significados atribuídos a ideia do turismo solidário. Nos terceiro e quarto tópicos, focase nas reflexões em torno dos encontros, discutindo questões referentes à construção da identidade pessoal por meio das relações sociais e como o aumento da intimidade pode aumentar o campo de possibilidades para resignificação identitária. No tópico cinco 
procura-se ilustrar as concepções teóricas desenvolvidas no artigo, apresentando as análises dos encontros entre visitantes e visitados no âmbito do Programa de Turismo Solidário do vale do Jequitinhonha.

\section{SOBRE O TURISMO SOLIDÁRIO}

Graburn (2001), ao comentar sobre o turismo solidário, relacionou-o com viagens praticadas em áreas pobres que incluem os que viajam a Cuba para ajudar com as colheitas da cana-de-açúcar e com o desenvolvimento local e ecológico; e ressalta que há também europeus que trabalham na Bolívia ajudando mineiros muito pobres a extrair estanho. Realça ainda o crescente sentido de responsabilidade moral da parte de muitos turistas, organizações não governamentais e alguns setores da promoção do turismo, para promover o turismo "amigo do pobre".

Por meio de sítios na rede mundial de computadores pode-se constatar que o termo turismo solidário está bastante difundido, mas possui vieses diferentes. Configurando, assim, um conceito em formação. A seguir, apresentam-se breves análises de alguns sítios eletrônicos sobre os significados atribuídos ao turismo solidário.

No sítio português www.inatel.pt, o turismo solidário é apresentado como uma oportunidade para as pessoas com dificuldades financeiras usufruírem do turismo; como fica evidenciado na citação abaixo:

Poderão participar do Programa cidadãos residentes em Portugal com idade superior a 18 anos, com um rendimento bruto mensal igual ou inferior a dois salários mínimos nacionais, poderão ser acompanhados pelos cônjuges, e/ou outros membros dependentes do agregado familiar, independente da idade e nacionalidade destes. O custo do Programa varia consoante o valor de rendimento bruto mensal por pessoa (INATEL, 2011).

Na França, no sítio www.tourisme-solidaire.org, o turismo solidário assemelhase ao caso do Vale do Jequitinhonha, tendo como foco a contribuição para habitantes dos países em desenvolvimento se fortalecerem economicamente. Organizações da sociedade civil fornecem apoio técnico às associações de moradores de países em desenvolvimento; elas, portanto, trabalham com projetos de desenvolvimento local e 
incentivam as pessoas a viajarem em direção aos locais carentes com o intuito de praticar o turismo solidário, tornando-se parte dos projetos de desenvolvimento.

$\mathrm{Na}$ Itália, no sítio www.turismosolidale.it, o turismo solidário é equacionado a um tipo de turismo chamado de "responsável" e possui uma rede de associações e entidades que promovem este tipo de atividade tanto no seu próprio território, como nos países considerados mais pobres.

Tanto a proposta francesa como a italiana defendem um tipo de turismo organizado pelas populações locais, pois acreditam que desta forma o dinheiro possa circular na região, contribuindo, assim, com o desenvolvimento local sem que haja a concentração da renda gerada pela atividade turística nas mãos de grandes agências (BELLIA; BATTESTI, 2004). Sendo assim, o turismo solidário também se aproxima do turismo de base comunitária, que tem como um dos seus pressupostos a questão do envolvimento dos moradores de uma determinada região na atividade turística e a valorização da cultura local (IRVING, 2009).

Uma agência de viagens na Argentina denominada de Boomerang oferece o turismo solidário como um dos seus produtos. Abaixo estão alguns trechos significativos retirados do sítio www.boomerangviajes.com.ar.

[...] contemplan espacios de intercambio con comunidades locales. Participación de sus tareas cotidianas. Algunos programas contemplan alojamiento en casas particulares. Involucran a comunidades indígenas y rurales. Contamos con programas en Argentina, América, África y Asia [...]. El viajero elige un destino a visitar. Por parte de Boomerang Viajes, se toma conocimiento sobre las motivaciones del viaje, los servicios requeridos por el viajero, el tiempo disponible, temporada y sus posibilidades económicas. El viajero es asesorado e informado acerca de los impactos que producirá su visita. El viajero identifica las necesidades básicas están cubiertas y realiza una propuesta en algunos casos las comunidades de base al contar ya con un proyecto se puede destinar un porcentaje para su desarrollo (BOOMERANGVIAJES, 2011) $)^{2}$.

Já a Action em seu sítio www.actionaid.org.br, apresenta-se como uma associação não governamental internacional, com atuação em 40 países, propondo:

\footnotetext{
${ }^{2}$ [...] contemplar espaços e compartilhar experiências com as comunidades locais. Participação das tarefas diárias. Alguns programas incluem alojamento privado. Envolver as comunidades indígenas e rurais. Temos programas na Argentina, América, África e Ásia [...]. O viajante escolhe um destino de visitar. Por meio da Boomerang viagens, o viajante entende as motivações da viagem, os serviços exigidos pelo viajante, o tempo disponível, sazonal e possibilidades econômicas. O viajante é aconselhado e informado sobre os impactos que produzem a sua visita. $\mathrm{O}$ viajante identifica se as necessidades básicas são atendidas e faz uma proposta, em alguns casos a comunidades já possui um projeto para alocar um percentual para o seu desenvolvimento.
} 
[...] desafios aos doadores de todo o mundo, e já levou turistas solidários à China, Índia, Peru, Quênia, Tanzânia, Camboja, Malauí, Sri Lanka e Marrocos. Entre os objetivos do desafio estão: arrecadar recursos para um fundo de emergências da organização, encurtar as distâncias entre países do Norte e do Sul, e chamar a atenção para o quanto às pessoas pobres ainda precisam de ajuda. Para participar da aventura, cada interessado se compromete com a ActionAid a arrecadar um montante junto a amigos , empresas, associações, etc., e passa por um treinamento sobre como levantar fundos (ACTIONAID, 2011).

Na Espanha um programa de turismo solidário é organizado pela Fundação Bancaja e o seu principal objetivo é levar os turistas para conhecer associações e projetos solidários espalhados pelo mundo podendo-se obter maiores informações no sítio www.obrasocial.bancaja.es/cultura/cultura.aspx. O intercâmbio cultural é estimulado através da hospedagem em receptivos familiares. Em um vídeo da Associação ${ }^{3}$, uma "turista solidária" caracteriza sua viagem dizendo: "um pouquinho de coração e sensibilidade é a melhor forma de viajar do mundo" e um turista, que parecia estar voltando a sua casa, salienta o enriquecimento obtido com a viagem ao dizer: "eu vou mais rico [...]. As pessoas não precisam oferecer seus serviços para a viagem ser caracterizada como solidária". Neste trecho, percebe-se, assim como no turismo solidário do Vale do Jequitinhonha (MG), que ações voluntárias não são primordiais para caracterizar o turismo solidário.

Outra modalidade de turismo que se assemelha às propostas do turismo solidário é o reality tour oferecido pela Global Exchange, para quem:

Tours are not designed to provide immediate solutions or remedy the world's most intractable problems, nor are they simply a brand of voyeurism [...]. A participant will have the chance to learn about unfamiliar cultures, meet with people from various walks of life, and establish meaningful relationships with people from other countries (GLOBALEXCHANGE, 2011).

E ainda aquela proposta pela cooperativa portuguesa "Mó de Vida", uma agência emissiva, para a qual: "o confronto com a realidade, tomando conhecimento no local visitado das desigualdades, injustiças, etc.; levará à adoção de atitudes mais

\footnotetext{
${ }^{3}$ Disponível em: 〈www.youtube.com/watch?v=eU5YQCzlmz8>.

${ }^{4}$ Os passeios não são projetados para fornecer soluções imediatas ou remediar problemas mais difíceis do mundo, nem são simplesmente uma marca de voyeurismo [...]. Um participante terá a oportunidade de aprender sobre culturas desconhecidas, encontrar com pessoas de várias estilos de vida, e estabelecer relacionamentos significativos com pessoas de outros países.
} 
solidárias nas suas vidas quotidianas" dos envolvidos nas atividades, conforme disponível no sítio eletrônico www.modevida.com/turismo.html.

Um dos casos mais significativos nessa abordagem dos sítios relacionados ao turismo solidário refere-se à organização dos estudantes da Oxford University, onde três deles, depois de uma viagem a regiões carentes da Geórgia, fundaram a "Travelaid" com intuito de organizar uma instituição que pudesse levar outros estudantes a terem experiências semelhantes (TRAVELAID, 2013). A instituição possui apoio da Universidade de Oxford; eles organizam viagens nas férias escolares para regiões carentes para que os alunos possam colocar suas habilidades a serviço das populações locais. Além disso, fazem campanhas para arrecadar fundos para os projetos sociais que se propõem a ajudar. Visto isso, tem-se que o turismo solidário basicamente proporciona um encontro entre visitantes e visitados, objeto de estudo neste artigo.

\section{CONSTRUÇÕES IDENTITÁRIAS E A QUESTÃO DO ENQUADRAMENTO}

Tendo em vista que o fenômeno turístico pressupõe encontros, é possível intuir que a partir da tomada de consciência pelos turistas de seu inacabamento enquanto ser social, tais encontros com o outro revelem um campo de possibilidades para seu próprio desenvolvimento pessoal.

Os seres humanos são indivíduos que buscam por reconhecimento no seio de um grupo em que possam se fortalecer mutuamente. A principal motivação para que tal fato ocorra é o mecanismo de diferenciação. Quando o grau de etnocentrismo presente nesse mecanismo e a necessidade de se recorrer a ele para se sentir "confortável" são amenizados, abrem-se novas possibilidades que permitem a resignificação da identidade do indivíduo e uma evolução no campo do saber, por meio de um movimento dialético entre diferentes maneiras de se perceber a realidade.

A percepção do outro como igual ou semelhante, que ocorre nos primeiros meses de vida quando o ser humano se descobre por meio do reconhecimento do outro frente aos seus atos intencionais (TOMASELLO, 2003), aparece como uma questão relevante para o desenvolvimento da espécie humana que pode ser encontrada também na idade adulta. 
Neste estudo, parte-se da ideia de que quando alguns traços que compõem a percepção do indivíduo em relação a si próprio são observados no outro, o mesmo sente-se atraído por si mesmo/pelo outro, visto que se faz presente o bem estar proporcionado pelo reconhecimento recíproco. Neste contexto, parte-se da premissa que existe uma questão biológica e social que sinaliza para a adoção do reconhecimento recíproco como meio de fortalecimento do sentimento de pertencimento.

Tomasello (2003, p. 99) apresenta indícios desse fato nos bebês ao refletir sobre a forma como os mesmos dão sentido as suas ações, visto que os outros são "como eu" e "qualquer nova compreensão de meu próprio funcionamento leva imediatamente a uma nova compreensão do funcionamento deles". Este fato ocorre porque o ser humano tem acesso ao mundo a partir da sua percepção individual, o que torna a sua percepção de mundo peculiar e contribui com a diversidade sociocultural.

Fernando Pessoa, em sua sensibilidade de poeta, ilustra a questão da percepção do indivíduo, declamando:

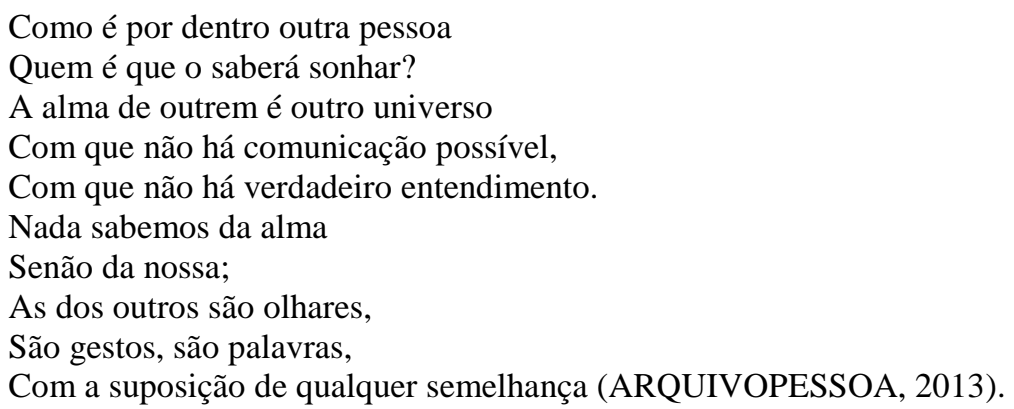

O trecho do poema apresenta como cada ser humano é parte de uma construção específica, apesar de compartilhar valores com seu grupo social/cultural. Sendo assim, recebem-se cotidianamente mensagens de pessoas inteiramente distintas apresentando um variado campo de possibilidades, no qual ocorre a formação pessoal do indivíduo.

Visto isso, tem-se que o ser humano é construído socialmente no seio das interações sociais nas quais se apresenta como sujeito capaz de selecionar um aspecto da realidade comum para que a comunicação possa ocorrer, mesmo que as diferenças entre os parceiros da comunicação forem marcantes. Fogel (1993) define este campo da realidade comum como enquadramento da relação, que é feito a partir de códigos específicos fornecidos pelo ambiente e pelo desenvolvimento da relação. 
Para que ocorra maior eficácia nessa comunicação, Tomasello (2003) destaca a importância da chamada "atenção conjunta" enquanto processo no qual a criança estabelece elementos/objetos em comum com os adultos para organizar e dar sentido à comunicação. Elemento importante para se pensar o encontro que se efetiva no campo do turismo, a ação conjunta se caracteriza, principalmente, pelo compartilhamento da atenção com o outro ao seguir os olhares dos sujeitos que interagem mediados por objetos, símbolos e significados negociados no processo interativo.

Neste processo, cria-se um campo de ação conjunta no qual os sujeitos da interação compartilham minimamente significados e modos de perceber a realidade. Nesta perspectiva, os encontros com símbolos e significados diferentes dos habituais revelam elementos importantes que permitem alargar o repertório do indivíduo para responder à realidade, de diferentes maneiras, criando, assim, um campo propício para a emersão de novas práticas.

Os humanos são responsáveis pelo "ordenamento" da sua identidade e, para isso, procuram eliminar o excesso de variáveis, o que significa vivenciar certas experiências e não outras, criando, assim, um mundo particular "confortável" que, ao se abrir a outros mundos, produz um alargamento do campo de possibilidades para que sejam forjadas novas identidades por meio de novos convívios.

O convívio pressupõe reconhecimento recíproco dos indivíduos em seus papéis sociais como sujeitos importantes. Para Honneth (2003, p. 158) "a autonomia subjetiva do indivíduo aumenta também com cada etapa de respeito recíproco [...] e o grau de relação positiva consigo mesma se intensifica passo a passo na sequencia das três formas de reconhecimento." Tais formas podem ser pensadas da seguinte maneira: reconhecimento recíproco no amor produz autoconfiança; no sistema jurídico, autorrespeito, e na solidariedade, autoestima (HONNET, 2003), e se apresentam como centrais para o encontro no campo do chamado turismo solidário.

Abaixo, pode-se observar um esquema hipotético (Figura 1) que sinaliza para a potencialidade da construção de novas identidades pautada pelo respeito mútuo, estima recíproca e pela valorização do "conhecimento tradicional". O fluxograma foi criado pelo autor para resumir a abordagem teórica apresentada no texto. 


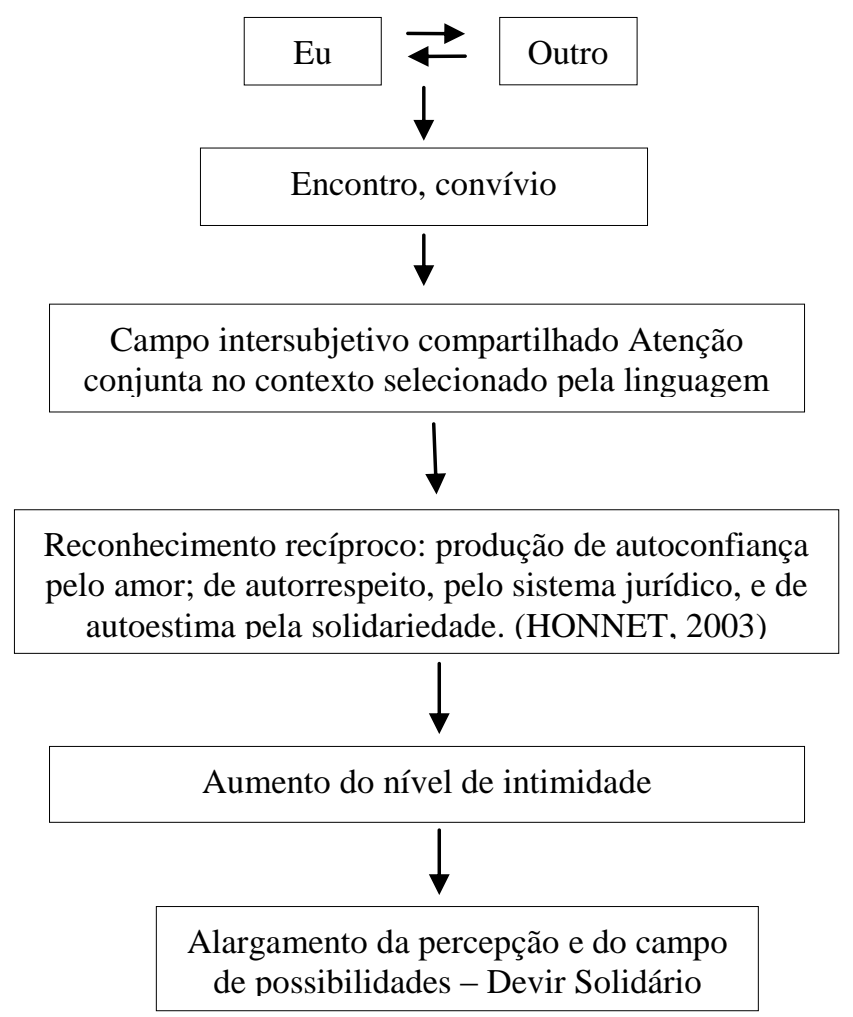

FIGURA 1 - ESQUEMA CONCEITUAL HIPOTÉTICO

FONTE: baseado em FORTUNATO (2011)

Em outras palavras, percebe-se que a estima recíproca entre sujeitos que compartilham modos de vidas escolhidos/construídos de formas diferenciadas contribui para o aumento do grau de solidariedade. Para Honneth (2003, p. 279), começa-se "a entrever um conceito de solidariedade social que aponta para uma estima simétrica entre cidadãos juridicamente autônomos".

Tal fato proporciona ao indivíduo a possibilidade de se beneficiar da experiência do outro evitando esforços que já foram realizados por seus semelhantes. Nesse caso beneficia-se da herança cultural, processo que se inicia na fase inicial da vida humana por meio da criação de um campo de atenção conjunta e interações.

\section{INTERAÇÃO HUMANA E CRIAÇÃO DE NOVOS SIGNIFICADOS}

A formação do indivíduo apresenta-se como uma construção social, pois, por meio de novos encontros surgem informações que podem compor um novo consenso 
sobre determinado assunto, configurando um movimento dialético marcado pelo devir (vir a ser).

No entanto, para que tal situação possa ocorrer necessita-se de uma negociação que não está presente previamente em cada indivíduo, mas que é construída no processo de interação social. Nesse sentido, Fogel (1993) comenta que o processo de formação da relação é contínuo e focaliza o progressivo aumento da intimidade entre os indivíduos como uma forma importante para compartilhar significados.

Vale ressaltar que essas questões relacionam-se com os encontros que ocorrem no campo do turismo solidário desenvolvido no Vale do Jequitinhonha, visto que diferente de outras modalidades de turismo, o turismo solidário proporciona aumento da intimidade e aprofundamento da relação estabelecida entre o visitante e as famílias com as quais convive. Neste contexto, os encontros que ocorrem no Vale podem ser pensados sob a perspectiva do momento em que os sujeitos compartilham símbolos e significados.

Parte-se do pressuposto que o aumento do tempo de hospedagem do indivíduo proporciona um aumento da intimidade e a possibilidade de redescrição identitária dos envolvidos no encontro. Como visto, trabalha-se com a ideia de que o compartilhamento de vivências, intimidades e significados propicia a emergência de situações propícias à emersão de novos olhares sobre a realidade. Nessa perspectiva, o processo de criação de intimidade, que ocorre em meio à variedade de temas produz negociações em busca de consensos e proporciona o desenvolvimento da relação.

O estudo das temáticas discutidas nas relações revela-se fundamental para se pensar no grau de intimidade presente entre os sujeitos da interação, bem como para se estabelecer novas reflexões em torno das questões socioambientais, pois tais questões apresentam-se, ao mesmo tempo, como problema e como potencialidade da região. Fazendo parte, portanto, do rol de assuntos discutidos.

Fogel (1993) salienta que algumas regras e normas sociais podem ser transformadas em uma relação de intimidade criando, assim, uma nova estrutura de significados para objetos e cenas por meio do relacionamento. Desse modo, tem-se que cada relação é única e pressupõe formas específicas de interação, fazendo do encontro e da relação um campo variável e dinâmico, tornando-se, portanto, uma relação que se apresenta em constante movimento criativo de discussão de novas temáticas. 
O processo de criação de novas informações e temas onde o individuo constrói sua identidade apresenta-se como um das principais questões para manter os sentidos da vida humana por meio do crescimento da relação e do aumento de intimidade e revelase importante para a construção da identidade dos indivíduos.

Entretanto, para Fogel (1993) a mesma relação pode ter significados diferentes para cada participante. A criação de novos consensos e de novas discussões temáticas entre os participantes de uma interação mantêm a dinamicidade da cultura e é responsável pelo salto qualitativo no processo do relacionamento, pois, a todo o momento, os seres humanos são afetados e afetam o ambiente com suas ações e escolhas. O levantamento das temáticas revelam o contexto no qual os encontros ocorrem e suas potencialidades.

\section{TEMÁtICAS DISCUTIDAS NOS ENCONTROS ENTRE TURISTAS E POPULAÇÃO LOCAL}

Durante os dias de convívio com as famílias e acompanhando os turistas no Vale do Jequitinhonha, algumas temáticas repetiram-se de forma expressiva. Logo no início dos encontros era corriqueiro ouvir-se falar das condições climáticas ("aqui está chovendo bastante"), das condições das estradas ("a estrada está muito ruim...") e de questões relacionadas à gastronomia, com o café sendo servido abria-se espaço às primeiras negociações sobre quais seriam os próximos temas a serem discutidos.

A interação logo se tornava dinâmica e os visitantes ou os visitados propunham novos temas e, depois de algumas horas de convívio, o aumento da intimidade revelava um universo de símbolos e significados até então encobertos pelo contato superficial dos primeiros momentos de encontro. Tal dinamicidade permitiu um aprofundamento dos assuntos abordados inicialmente de forma superficial como, por exemplo, quando se retornava aos temas relacionados à gastronomia, eles ganhavam profundidade com uma análise do modo de produção, ao mesmo tempo em que assumiam características próprias ao serem mencionados em suas especificidades de "frango ao molho pardo" e de "umbigo de banana". 
Outros temas recorrentes referem-se aos aspectos profissionais de cada indivíduo envolvido na relação para realização das dinâmicas produtivas. Uma turista, que realizava uma ação voluntária na área de saúde, mostrou-se interessada na percepção dos moradores sobre os profissionais que trabalham no campo da medicina, por ser inviável obter tal visão na universidade.

A temática da violência na cidade grande foi acionada em diversos momentos nos encontros, visto que os turistas entrevistados para realização desta pesquisa moravam em grandes centros. Em um deles, com uma menina de aproximadamente oito anos, ocorreu um fato peculiar, pois a mesma questionou a turista que realizava ações voluntárias sobre o significado de dois termos usados frequentemente nos grandes centros, "traficante" e "ameaça". Isso, pois tais símbolos linguísticos não faziam parte do repertório da criança. Neste caso, a turista precisou utilizar símbolos correlatos para manter certa coerência na comunicação.

O grau de intimidade crescia nitidamente com o passar das horas de convívio e, ao final do dia, as temáticas a serem abordadas eram negociadas com maior rapidez/fluidez e questões íntimas, como preocupações com o futuro dos filhos, sentimentos em relação aos familiares falecidos e, até mesmo manias ao dormir, emergiam da interação.

Para evidenciar que o aumento da intimidade promove situações de compartilhamento de assuntos considerados como de maior intensidade, estabeleceu-se um parâmetro crescente para a análise da intimidade estabelecida nos encontros entre a população local e os turistas no âmbito do Programa de Turismo Solidário do Vale do Jequitinhonha, tendo como indicadores/categorias de análise o nível um e dois (pouca intimidade) três e quatro (intimidade média) e cinco (intimidade alta), a partir das questões abaixo enunciadas, acredita-se que tal escala pode contribuir com outros estudos que desejarem aprimorar tal opção metodológica para estudar os encontros no campo do turismo, baseando-se no estabelecimento da intimidade entre visitantes e visitados com a troca de experiências.

1. Clima/relevo/infraestrutura (Tem chovido muito aqui? Quais as consequências das chuvas nas estradas? Que caminhos permitem chegar até aqui?).

2. Alimentação/gastronomia (Conhece este alimento? Quer café? Broa de milho? Garapa?). 
3. Atualidades/notícias/mídia (Como é a vida na sua cidade? É verdade o que se vê no noticiário?).

4. Profissões/livro (Com o que você trabalha? Como é essa atividade produtiva? Gosta de ler?).

5. Relevância emocional (O que você gosta de fazer? O que lhe dá prazer? Casos de infância, sentimentos em relação à família, aos amigos, espiritualidade e reflexões sobre o sagrado).

As situações descritas podem ser visualizadas no gráfico 1. Procura-se sistematizar uma (co) relação entre o tempo do encontro, o aumento da intimidade e à troca de experiência com a construção da identidade dos atores sociais envolvidos nos encontros.

Intimidade/Trocas

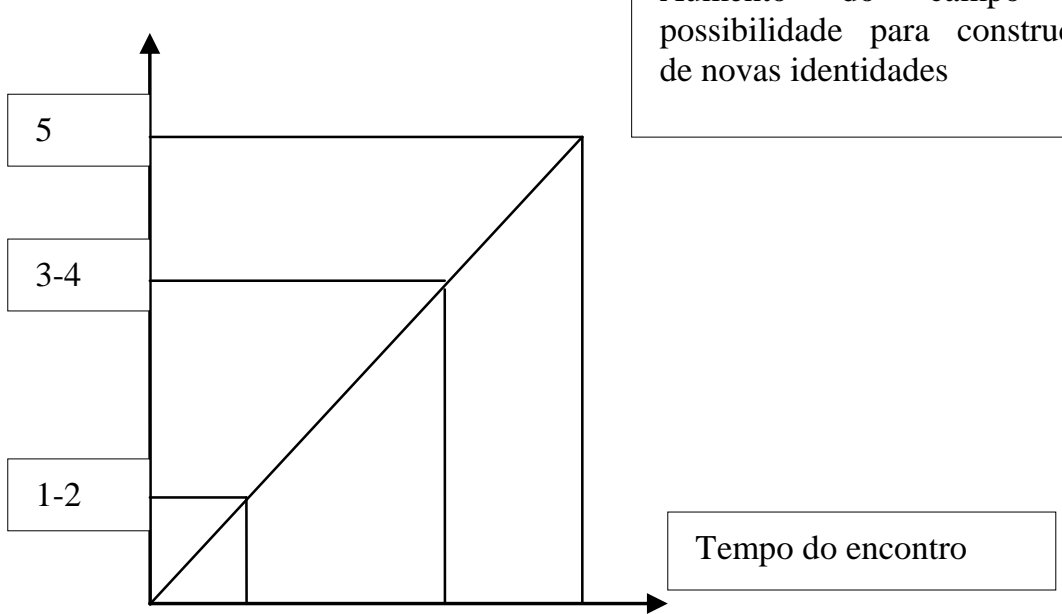

GRÁFICO 1 - A RELAÇÃO TEMPORAL COM O AUMENTO DO NÍVEL DE INTIMIDADE FONTE: FORTUNATO (2011)

Vale ressaltar que a variável tempo é relativa, pois intimidade e trocas experienciais podem alcançar o nível cinco, tanto em uma semana como em apenas um dia de convívio. Segundo um dos turistas solidários, que propunha a sistematização do conhecimento popular em relação às plantas medicinais da região, nesta modalidade de turismo "quanto mais o tempo vai passando, mais os laços vão se fortalecendo". 
Caso o encontro já tenha ocorrido em outro momento, as etapas um e dois tendem a ser breves. O nível cinco corresponde a um maior nível de intimidade e, na maioria das vezes, pressupõe um maior tempo de relação com o outro.

Dessa maneira percebe-se que, com o aumento do grau de intimidade entre os interlocutores, são revelados modos de percepção da realidade cada vez mais peculiares, únicos, específicos, com construções que expressam determinados símbolos em detrimento de outros para representar a realidade, evidenciando, assim, as potencialidades dos encontros com o outro, quando aceito e compreendido em suas diferenças.

Neste contexto, abrem-se novas potencialidades para se pensar na interação como um espaço de formação pessoal e de resignificação identitária, visto que coloca diante do sujeito um maior repertório para construção da sua identidade, pois para Littlejohn e Foss (2005) o ser humano afeta o mundo, mas também é afetado por ele. Todo ser humano sofre influências externas e no encontro marcado pelo reconhecimento recíproco proporcionado pela lógica que aproxima e une ao invés de separar, podem ser encontrados elementos importantes para a constituição da ética da religação que "engloba tudo aquilo que faz comunicar, associar, solidarizar, fraternizar; ela se opõe a tudo o que fragmenta, desloca" (MORIN, 1998, p. 72). Este mesmo autor chamou esse processo de reconhecimento mútuo, no qual existe a consciência que a formação do indivíduo perpassa pelo modo como ele se relaciona com a alteridade e que é por meio dessas relações que as pessoas se humanizam.

\section{CONSIDERAÇÕES FINAIS}

Por meio deste artigo percebeu-se como os estudos no campo do turismo, mais especificamente, dos encontros no campo do turismo, podem ganhar consistência teórica ao utilizar abordagens relacionadas à comunicação e a interação humana (FOGEL, 1993; LITTHLEJHON e FOSS, 2005; TOMASELLO, 2003; HONETH, 2003), demonstrando, assim, o caráter transdisciplinar do fenômeno turístico.

A escolha do turismo solidário para observar os encontros no campo do turismo revelou o modo de vida da população do Vale do Jequitinhonha e suas percepções sobre 
a realidade, pois colocou diante dos turistas situações de interação e de compartilhamento de símbolos e significados em um ambiente familiar.

Observou-se que o contato e o maior tempo de convivência permitem ao turista um aprofundamento da relação e o rompimento do contato superficial. Observou-se, também, que tal contato adquire características de amizade e as negociações dos temas a serem discutidos passam a ocorrer com maior espontaneidade e dinamicidade. Nesse processo, tanto os visitantes como os visitados adquirem uma postura que permite revelar-se um ao outro, pois os visitantes compartilham o espaço domiciliar dos moradores locais, no qual as relações mais profundas costumam ser mais intensas.

A presença do turista afeta o ambiente familiar, pois, certo receio dos moradores em não agradar ao turista com as condições da casa e com a qualidade da alimentação pôde ser percebido nos encontros, mas não impediram que a interação ocorresse podendo alcançar o nível cinco (intimidade alta).

Visto isso, os encontros no campo do turismo solidário podem ser considerados momentos propícios para formação pessoal e resignificação identitária, visto que símbolos e significados específicos, representados pela construção social de indivíduos em ambiente distintos, encontram-se como elementos relativizadores de pontos de vistas e de modos de ser e estar no mundo contemporâneo.

O convívio com aumento no grau de intimidade entre os sujeitos envolvidos no encontro faz desse tipo de turismo uma busca por pessoas mais do que por paisagens. $\mathrm{O}$ outro é o diferencial, o outro é o que mais importa, o outro é o responsável por aumentar os repertórios temáticos pelos quais os indivíduos são capazes de "circular". Tais características atribuídas aos encontros abrem possibilidades para se pensar nos mesmos como um fenômeno que estimula o reconhecimento e a convivência.

Neste sentido, turismo, identidade, comunicação e interação tornam-se elementos convergentes e contribuem para a análise de cunho transdisciplinar sobre o fenômeno do encontro no campo do turismo. 


\section{REFERÊNCIAS}

ACTIONAID. Disponível em:

<http://www.actionaid.org.br/Portals/0/Releases/Especial/turismo_solidario.pdf > .

Acesso em: 02/02/2011.

ARQUIVO PESSOA. Disponível em: <http://arquivopessoa.net/textos/2784>. Acesso em: $22 / 01 / 2013$

BANCAJA. Disponível em: <http://www.obrasocial.bancaja.es/cultura/cultura.aspx>. Acesso em: 22/01/2013

BELLIA, R; BATTESSI, N. R. Tourisme solidaire: innovation et réseau: analyse comparée France-Italie. In : Colloque Les enjeux du management responsible. Lyon, Université Catholique de Lyon, 2004, p.18-19.

BOOMERANGVIAJES. Disponível em:

<http://www.boomerangviajes.com.ar/espanol/turismosolidario.php >. Acesso em: $05 / 04 / 2011$

CAPALBO, C. Fenomenologia e ciências humanas. Rio de Janeiro: Âmbito cultural, 1987.

FOGEL, A. Developing through relationships origins of communication, self, and culture. Chicago: Univ. of Chicago Press, 1993.

FORTUNATO, R. A. Turismo solidário e a redescrição social no Vale do Jequitinhonha-MG. 163p. Tese. Universidade do Estado do Rio de Janeiro. Rio de Janeiro, 2011.

FORTUNATO, R. A.; NEFFA, E. M. Entraves e potencialidades de ações voluntárias na região do Programa de Turismo Solidário do Vale do Jequitinhonha. Revista Turismo \& Sociedade, Curitiba, v. 3, n. 2, p. 185-202, outubro de 2010a: UFPR. Disponível em:

<http://ojs.c3sl.ufpr.br/ojs2/index.php/turismo/article/view/19630/12827)>.

A articulação SEDVAN-IDENE: perspectivas e potencialidades socioambientais na região do Alto Vale do Jequitinhonha/MG: o caso do Programa de Turismo Solidário. Revista Observatório de Inovação do Turismo, Rio de Janeiro, v. 5, n. 4, p. 01-21, novembro de 2010b: FGV. Disponível em:

$<$ http://app.ebape.fgv.br/revistaoit/asp/dsp_lst_artigos_edicao.asp?coded=120>.

GLOBAL EXCHANGE. Disponível em:

<http://www.globalexchange.org/tours/faq.html>. Acesso em: 02/02/2011. 
GRABURN, N. Secular ritual: a general theory of tourism. In: Smith V, Brent M (Org.). Hosts and Guests Revisited: Tourism Issues of the 21st Century. Cognizant Communication Corporation: New York; p. 42-50, 2001.

HONNETH, A. Luta por reconhecimento: a gramática moral dos conflitos sociais. São Paulo: Ed. 34, 2003.

HUSSERL, E. A ideia da fenomenologia. Lisboa, Edições 70, 2008.

INATEL. Disponível em: <http://www.inatel.pt/Turismo/programas/solidario.pdf>. Acesso em: 02/02/2011.

IRVING, M. de A. Reinventando a reflexão sobre turismo de base comunitária: inovar é possível? In: BARTHOLO, R.; SANSOLO, D. G.; BURSZTYN, I. (Orgs.). Turismo de Base Comunitária: diversidade de olhares e experiências brasileiras. Rio de Janeiro: Letra e Imagem, 2009.

LAPASSADE, G. L'entrée dans la vie. Essai sur l'inachèvement de l'homme. Paris, Minuit, 1963.

LITTLEJOHN, S; FOSS, K. Theories of human communication. Belmont, California: Thompson Wadsworth, 2005.

MACHADO, O. V. Pesquisa qualitativa: modalidade fenômeno situado: In: BICUDO, M. A. V. e ESPOSITO, V. H. S. (Orgs.). A pesquisa qualitativa em educação: um enfoque fenomenológico. Piracicaba: UNIMEP, 1994. p. 35-46.

MÓ DE VIDA. Disponível em: <http://www.modevida.com/turismo.html>. Acesso em: 02/02/2011.

MORIN, E. Ética, solidariedade e complexidade. São Paulo: Palas Athena, 1998.

OLIVEIRA, I. B. Aprendendo nos/dos/com os cotidianos a ver/ler/ouvir/sentir o mundo. Educ. Soc., Abr. 2007, v. 28, n. 98, p. 47-72.

STEIL, C. A. Romeiros e turistas no santuário de Bom Jesus da Lapa. Horizontes Antropológicos, Out. 2003, v. 9, n. 20, p. 249-261.

TOMASELLO, M. Origens culturais da aquisição do conhecimento humano. São Paulo: Martins Fontes, 2003.

TOURISMESOLIDAIRE. Disponível em:

$<$ http://www.tourisme-solidaire.org/ressource/pdf/ts_reseau.pdf $>$. Acesso em: 04/04/2011.

TRAVELAID. Disponível em: <http://www.travelaid.org.uk>. Acesso em: 22/01/2013 
TURISMOSOLIDARIO. Disponível em: 〈http://www.turismosolidario.com.br>. Acesso em: 20/03/2009.

TURISMOSOLIDALE. Disponível em: <http://www.turismosolidale.it>. Acesso em: $23 / 01 / 2013$

TURNER, V; TURNER, E. Image and pilgrimage in Christian culture. New York: Columbia University Press, 1978.

Recebido em: 25-04-2012

Aprovado em: 25-05-2012. 